\title{
Tidal expiratory flow limitation, dyspnoea and exercise capacity in patients with bilateral bronchiectasis
}

\author{
N.G. Koulouris*, S. Retsou*, E. Kosmas*, K. Dimakou*, K. Malagari*, G. Mantzikopoulos*, \\ A. Koutsoukou*, J. Milic-Emili\#, J. Jordanoglou*
}

Tidal expiratory flow limitation, dyspnoea and exercise capacity in patients with bilateral bronchiectasis. N.G. Koulouris, S. Retsou, E. Kosmas, K. Dimakou, K. Malagari, G. Mantzikopoulos, A. Koutsoukou, J. Milic-Emili, J. Jordanoglou. C)ERS Journals Ltd 2003.

ABSTRACT: In this study the authors investigated whether expiratory flow limitation (FL) is present during tidal breathing in patients with bilateral bronchiectasis (BB) and whether it is related to the severity of chronic dyspnoea (Medical Research Council (MRC) dyspnoea scale), exercise capacity (maximal mechanical power output (WRmax)) and severity of the disease, as assessed by high-resolution computed tomography (HRCT) scoring.

Lung function, MRC dyspnoea, HRCT score, WRmax and FL were assessed in 23 stable caucasian patients (six males) aged $56 \pm 17$ yrs. FL was assessed at rest both in seated and supine positions. To detect FL, the negative expiratory pressure (NEP) technique was used. The degree of FL was rated using a five-point FL score. WRmax was measured using a cyclo-ergometer.

According to the NEP technique, five patients were FL during resting breathing when supine but not seated, four were FL both seated and supine, and 14 were NFL both seated and supine. Furthermore, it was shown that: 1) in stable BB patients FL during resting breathing is common, especially in the supine position; 2) the degree of MRC dyspnoea is closely related to the five-point FL score; 3 ) WRmax (\% pred) is more closely correlated with the MRC dyspnoea score than with the five-point FL score; and 4) HRCT score is closely related to forced expiratory volume in one second \% pred but not five-point FL score.

In conclusion, flow limitation is common at rest in sitting and supine positions in patients with bilateral bronchiectasis. Flow limitation and reduced exercise capacity are both associated with more severe dyspnoea. Finally, high-resolution computed tomography scoring correlates best with forced expiratory volume in one second.

Eur Respir J 2003; 21: 743-748.
*Dept of Respiratory Medicine, Respiratory Function Laboratory, University of Athens Medical School, "Sotiria" Hospital, Athens, Greece. ${ }^{\#}$ Meakins-Christie Laboratories, McGil University, Montreal, Quebec, Canada.

Correspondence: N. G. Koulouris Respiratory Function Laboratory Dept of Respiratory Medicine University of Athens

"Sotiria" Hospital for Diseases of the Chest 152, Mesogion Ave Athens, GR-115 27

Greece

Fax: 302107770423

E-mail: koulnik@med.uoa.gr

Keywords: Bronchiectasis exercise

high-resolution computed tomography negative expiratory pressure

pulmonary function

respiratory mechanics

Received: December 52001

Accepted after revision: December 122002
Bronchiectasis is characterised by irreversible destruction of airways, mainly related to chronic infection. Although this condition is presently rare in the developed countries, particularly North America, it is still common in the underdeveloped world where it causes considerable morbidity and mortality [1]. Although an obstructive pulmonary defect is found in the majority of these patients, a mixed obstructive/ restrictive defect is not uncommon [1-5]. The disease presents with varying degrees of fibrotic and emphysematous changes due to chronic lung inflammation, which eventually lead to chronic respiratory failure and severe disability [1-5]. Chronic dyspnoea is a common complaint [6] and exercise capacity may be reduced.

Patients with chronic obstructive pulmonary disease (COPD) exhibit chronic dyspnoea and reduced exercise capacity, mainly as a result of tidal expiratory flow limitation (FL), with concurrent dynamic hyperinflation and inspiratory loading due to intrinsic positive end-expiratory pressure (PEEPi), and reduction of inspiratory muscle force [7-12]. It is not known if tidal FL is present in patients with bronchiectasis nor if it plays a role in chronic dyspnoea and exercise limitation, except in patients with cystic fibrosis. In this condition, which is also characterised by bronchiectasis, tidal FL is seldom present at rest and, if absent, the Medical
Research Council (MRC) dyspnoea score is low [13] and there is little or no impairment of exercise capacity [14].

Accordingly, in the present study on 23 stable patients with bilateral bronchiectasis (BB) the authors have assessed if expiratory FL is present during tidal breathing and if it is related to the severity of chronic dyspnoea (MRC scale), exercise capacity and severity of the disease, as assessed by high-resolution computed tomography (HRCT) scoring.

\section{Methods}

The study was performed on 23 caucasian patients with BB. No patient was a current or exsmoker. The diagnosis was based on clinical history and HRCT scans. Eleven patients had post-tuberculosis and 12 postinfective bronchiectasis. None of the patients underwent surgery concerning bronchiectasis or other thoracic disease. At the time of this study their clinical and functional state was stable for at least 4 weeks. According to sputum culture patients can be classified into the Pseudomonas aeruginosa (PA) group, i.e. six patients who were colonised with $P$. aeruginosa, and the non-PA group, i.e. eight patients colonised with "normal flora", seven Haemophilus influenzae, one Acinetobacter and one Serratia. 
Table 1.-Modified Medical Research Council dyspnoea scale

\begin{tabular}{lll}
\hline Category & Degree & \multicolumn{1}{c}{ Definition } \\
\hline 0 & None & Not troubled by dyspnoea \\
1 & Slight & Troubled by shortness of breath when hurrying on the level or walking up a slight hill \\
2 & Moderate & Walks slower than people of the same age on the level because of breathlessness \\
3 & Moderately severe & Has to stop because of breathlessness when walking at own pace on the level \\
4 & Severe & Stops for breath after walking about 100 yards or a few minutes on the level \\
5 & Very severe & Too breathless to leave the house or breathless when dressing or undressing \\
\hline
\end{tabular}

Modified from [15, 16].

All patients were familiar with routine respiratory measurements and dyspnoea evaluation. Patients with a history of COPD, asthma, sleep apnoeas, other concomitant lung disease, cardiovascular disorders, obesity and other serious acute or chronic disease were excluded. Cystic fibrosis was excluded on the basis of a sweat test. The study had the approval of the institutional ethical committee and informed consent was obtained from all patients.

The severity of chronic dyspnoea was rated according to the modified MRC chronic dyspnoea scale [15] (table 1). Forced spirometry was measured with a screen pneumotachograph (Screenmate; Erich Jaeger GmbH \& Co., Höchberg, Germany). Total lung capacity (TLC) and its subdivisions were assessed with the helium-dilution method.
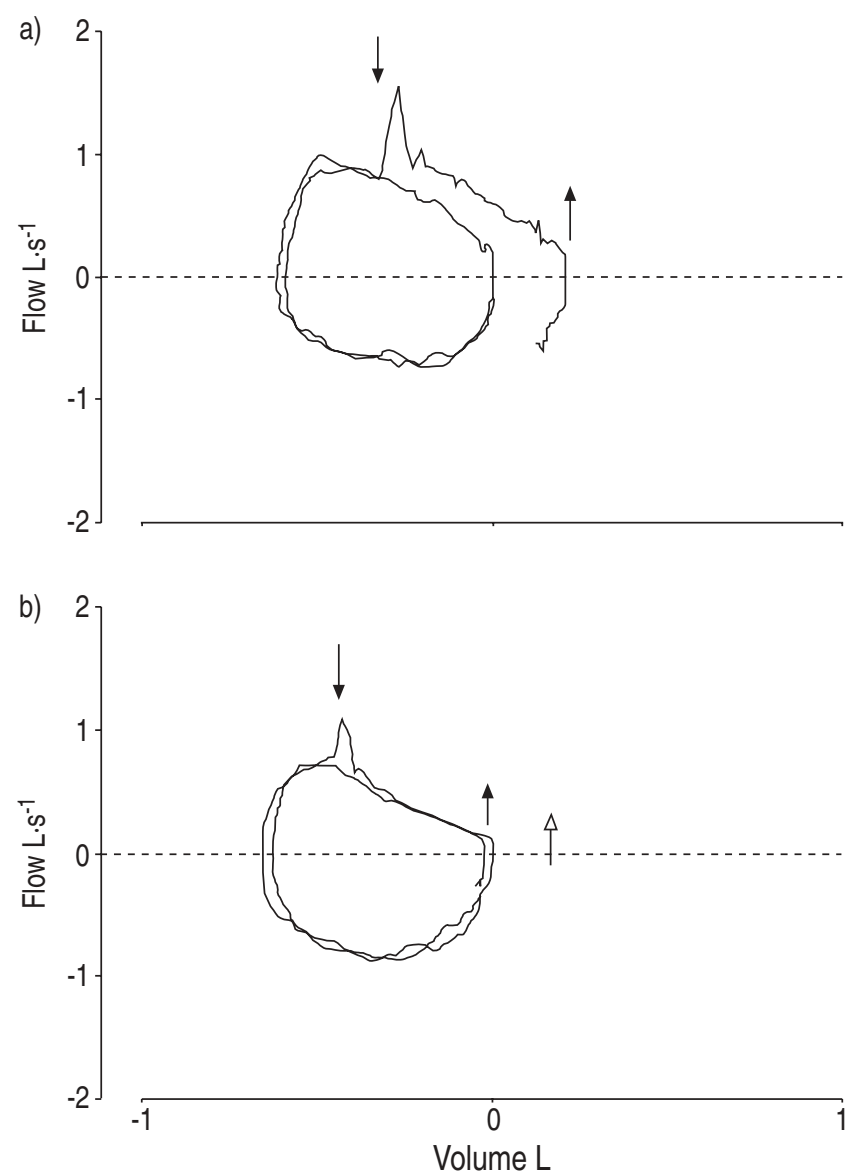

Fig. 1.-Flow/volume loops of test breaths and preceding control breaths of two representative bronchiectatic patients with different degrees of flow limitation: a) not flow limited (patient no. 12); b) flow limited over $<50 \%$ tidal volume (patient no. 21). Solid arrow: points at which negative expiratory pressure was applied and removed; open arrow: expiration.
Carbon monoxide transfer factor $(T \mathrm{~L}, \mathrm{CO})$ was determined by the single breath-hold method (Benchmark Transfer Test; PK Morgan, Rainham, UK). The predicted spirometric values, static lung volumes and TL,CO are from the European Coal and Steel Community [17]. The arterial oxygen and carbon dioxide pressures $\left(\mathrm{Pa}, \mathrm{O}_{2}\right.$ and $\mathrm{Pa}, \mathrm{CO}_{2}$ respectively) were measured with a blood gas analyser (288 Blood gas system; Ciba-Corning, MA, USA).

The experimental set-up used to assess expiratory FL during spontaneous breathing has been described in detail elsewhere [18-20]. Briefly, a flanged plastic mouthpiece is connected to a pneumotachograph (Screenmate-Box; Erich Jaeger $\mathrm{GmbH} \& \mathrm{Co}$.) and a T-tube. One side of the T-tube is open to the atmosphere, whilst the other side is equipped with a one-way pneumatic valve (Series 9300; Hans Rudolph, Inc., Kansas City, MO, USA). This allows for the subject to be rapidly switched (Hans Rudolph control switch 9301) to negative expiratory pressure (NEP) generated by a vacuum cleaner (Model S204; Miele Electronic de Lux, Miele, Germany). The NEP $\left(-3.5 \mathrm{cmH}_{2} \mathrm{O}\right)$ could be adjusted with a potentiometer incorporated into the vacuum cleaner. Flow $\left(V^{\prime}\right)$ was measured with the heated pneumotachograph and pressure at the airway opening was measured through a side port on the mouthpiece using a differential pressure $\left( \pm 50 \mathrm{cmH}_{2} \mathrm{O}\right)$ transducer (Screenmate-Box; Erich Jaeger Gmbh $\&$ Co). Volume $(V)$ was obtained by digital integration of the flow signal. The NEP test compares the tidal expiratory $V^{\prime} / V$ curve obtained during a control breath with that obtained during the subsequent expiration in which NEP is applied (fig. 1). Subjects in whom application of NEP did not elicit an increase of flow during part or all of the tidal expiration were considered FL. In contrast, subjects in whom flow increased with NEP throughout the control tidal volume range were considered as non-FL (NFL) [18].

Using the NEP technique, FL was assessed in the $23 \mathrm{BB}$ patients randomly in seated and supine positions $[16,18]$. The degree of FL was scored using the five-category classification (five-point FL score) shown in table 2.

All patients underwent HRCT scanning within 2 weeks before the experimental part of the study in order to assess the severity of the disease. Two experienced radiologists, who were not aware of the specific scope of the study, independently reviewed and scored the scans. The mean score

Table 2.-Classification of flow limitation (FL) into five categories according to fraction of control tidal volume (VT) encompassed by $\mathrm{FL}(\mathrm{FL} \% \mathrm{~V} T)$ and body position

\begin{tabular}{lccc}
\hline Category & Supine & Seated & Degree \\
\hline 0 & NFL & NFL & None \\
1 & FL $<50 \% V \mathrm{~T}$ & NFL & Mild \\
2 & FL $>50 \% V \mathrm{~T}$ & NFL & Moderate \\
3 & FL & FL $<50 \% V \mathrm{~T}$ & Severe \\
4 & FL & FL $>50 \% V T$ & Very severe \\
\hline
\end{tabular}

Modified from [16]. 
value from the radiologists was used (HRCT score). Scoring was obtained using the method of BHALLA et al. [21] by assessing the following nine morphological parameters: 1) severity of bronchiectasis, 2) extent of bronchiectasis, 3) peribronchial thickening, 4) extent of mucus plugging, 5) generations of bronchial divisions involved, 6) abscesses or bronchiectatic sacculations, 7) number of bullae, 8) emphysema and 9) collapse/consolidation. Items 1-7 have a threepoint score, while items $8-9$ have a score of two. Thus, the highest cumulative score that can be generated from the above parameters is 25 .

\section{Procedure}

Immediately prior to the study, the severity of chronic dyspnoea was self-evaluated (table 1) and arterial blood gases were measured. Next, routine spirometry and tidal FL were assessed in a random order while seated upright in a comfortable chair or lying supine on a comfortable couch, at least $2 \mathrm{~h}$ after eating or drinking coffee. Patients were asked to breathe room air through the equipment assembly with the noseclip on. Each subject had an initial 10-15 min trial run, in order to become accustomed to the apparatus and procedure. The pneumotachogram was continuously monitored on the screen of the computer. When regular breathing had been achieved, a series of test breaths were performed, in which NEP $\left(\sim-3.5 \mathrm{cmH}_{2} \mathrm{O}\right)$ was applied at the beginning of expiration and maintained throughout the ensuing expiration. Figure 1 shows typical $V^{\prime} / V$ loops of NEP test breaths and preceding control breaths of two patients. In patient no. 12 application of NEP resulted in an increase in flow throughout the ensuing expiration, indicating absence of FL (NFL), while in patient no. 21 application of NEP did not increase the flow over the $44 \%$ of the control tidal volume $(V \mathrm{~T})(\mathrm{FL}=44 \% V \mathrm{~T})$.

An incremental symptom-limited exercise test was also performed by 15 of the 23 patients, using an electrically braked cycled ergometer (Model A1; Instrumenten Lode NV, Groningen, the Netherlands) and an automated cardiopulmonary exercise system (Benchmark Exercise Test; PK Morgan Ltd, Rainham, UK). After a 3 min warming-up period, patients cycled at 50-60 revolutions per minute with the external power increased in 1-min steps of 20 watts to the limit of their tolerance. Oxygen saturation, heart rate and arterial pressure were continuously monitored with a vital signs monitor attached to the metabolic chart (Monitor M-1; PK Morgan Ltd). The patients were encouraged during the exercise test to reach their maximum. In this way, their maximal mechanical power output (WRmax) was determined. The predicted normal values for WRmax were those of JONES [22]. There was no evidence of bronchospasm in any of the patients during or after the procedure.

\section{Statistical analysis}

Values are presented as mean \pm SD. One-way analysis of variance (Student Neuman-Keuls test) was used, in order to make multiple comparisons for each parameter studied in the NFL, FL supine and FL seated and supine groups. The unpaired t-test was used to detect statistically significant differences of all parameters studied in postinfective versus post-tuberculosis, and PA versus non-PA BB patients. Pearson's correlation coefficients $(r)$ and linear regression analyses were used to assess correlations of WRmax (\% pred) and HRCT score to all variables studied, in order to ascertain which parameters correlated best. For the MRC dyspnoea score, since it is an ordinal categorical variable, the Spearman rank correlation coefficient $\left(r_{s}\right)$ was calculated, as it is appropriate for such data. A p $<0.05$ was taken as statistically significant.

\section{Results}

The anthropometric characteristics and baseline lung function data of the patients are given in table 3 . Eleven patients had obstructive, nine mixed (obstructive/restrictive) and one restrictive lung defects, while two patients had lung function within the normal range. Fourteen patients were NFL, five were FL only supine and four were FL both seated and supine. Of the nine patients who were FL seated and/or supine, two had obstructive and seven mixed lung defects, while the patients with restrictive defect or normal lung function were NFL. Nine of the patients with obstructive lung defect were NFL.

The patients with postinfective and post-tuberculosis bronchiectasis had no statistically significant differences in baseline lung function, MRC, five-point FL and HRCT scores, or WRmax ( $\%$ pred) data.

In contrast, compared to the non-PA group, the PA patients had poor lung function (table 4). In addition, they had higher MRC, five-point FL and HRCT scores and a lower WRmax (\% pred).

Lung function was better preserved in the NFL group. The

Table 3. - Anthropometric, pulmonary and dyspnoea data of bronchiectatic patients without (NFL) and with flow limitation $(\mathrm{FL})$ supine, or seated and supine

All patients NFL FL supine $\begin{gathered}\begin{array}{c}\text { FL seated } \\ \text { and supine }\end{array} \\ \text { N }\end{gathered}$

\begin{tabular}{|c|c|c|c|c|}
\hline Subjects $\mathrm{n}$ & 23 & 14 & 5 & 4 \\
\hline Sex M:F & $6: 17$ & $2: 12$ & $4: 1$ & $0: 4$ \\
\hline Age yrs & $56 \pm 17$ & $52 \pm 17$ & $71 \pm 10$ & $51 \pm 14$ \\
\hline Height $\mathrm{cm}$ & $162 \pm 7$ & $161 \pm 6$ & $168 \pm 8$ & $158 \pm 3$ \\
\hline Weight $\%$ pred & $103 \pm 15$ & $101 \pm 16$ & $105 \pm 12$ & $109 \pm 13$ \\
\hline FVC $\%$ pred & $81 \pm 27$ & $96 \pm 20$ & $63 \pm 17 * *$ & $49 \pm 16^{* * *}$ \\
\hline FEV1 \% pred & $64 \pm 29$ & $82 \pm 21$ & $43 \pm 11 * * *$ & $28 \pm 6 * * *$ \\
\hline FEV1/FVC \% & $64 \pm 15$ & $71 \pm 13$ & $55 \pm 15 *$ & $52 \pm 9 *$ \\
\hline FEV1/FVC $\%$ pred & $82 \pm 19$ & $90 \pm 17$ & $74 \pm 20$ & $65 \pm 12 *$ \\
\hline PEF \% pred & $71 \pm 28$ & $84 \pm 25$ & $52 \pm 23 *$ & $49 \pm 15 *$ \\
\hline FEF $25-75 \% \%$ pred & $36 \pm 34$ & $52 \pm 35$ & $17 \pm 7 *$ & $6 \pm 2 *$ \\
\hline FEF $75 \% \%$ pred & $31 \pm 29$ & $44 \pm 30$ & $16 \pm 7 *$ & $6 \pm 4^{*}$ \\
\hline IC $\%$ pred & $80 \pm 25$ & $93 \pm 19$ & $58 \pm 15 * *$ & $63 \pm 25^{*}$ \\
\hline ERV \% pred & $83 \pm 51$ & $102 \pm 46$ & $78 \pm 45$ & $20 \pm 5 * *$ \\
\hline TLC $\%$ pred & $78 \pm 16$ & $85 \pm 10$ & $70 \pm 15 *$ & $64 \pm 22 *$ \\
\hline FRC $\%$ pred & $77 \pm 18$ & $82 \pm 17$ & $74 \pm 15$ & $61 \pm 16$ \\
\hline RV \% pred & $77 \pm 19$ & $74 \pm 15$ & $77 \pm 21$ & $89 \pm 29$ \\
\hline FRC/TLC \% & $54 \pm 7$ & $53 \pm 7$ & $59 \pm 8$ & $54 \pm 5$ \\
\hline RV/TLC \% & $37 \pm 11$ & $31 \pm 8$ & $44 \pm 10 * *$ & $51 \pm 5 * * *$ \\
\hline$T \mathrm{~L}, \mathrm{CO} \%$ pred & $70 \pm 23$ & $78 \pm 21$ & $70 \pm 14$ & $41 \pm 21 *$ \\
\hline$P \mathrm{a}, \mathrm{O}_{2} \mathrm{mmHg}$ & $74 \pm 13$ & $80 \pm 10$ & $71 \pm 9$ & $60 \pm 18 *$ \\
\hline $\mathrm{Pa}, \mathrm{CO}_{2} \mathrm{mmHg}$ & $41 \pm 5$ & $40 \pm 5$ & $43 \pm 4$ & $42 \pm 8$ \\
\hline $\begin{array}{l}\text { MRC dyspnoea } \\
\text { score }\end{array}$ & $1.8 \pm 1.2$ & $1.1 \pm 0.6$ & $2.2 \pm 0.5^{* *}$ & $3.8 \pm 1.0 * * *$ \\
\hline
\end{tabular}

Data are presented as mean \pm SD. M: male; F: female; \% pred: percentage of predicted; FVC: forced vital capacity; FEV1: forced expiratory volume in one second; PEF: peak expiratory flow; FEF25-75\%: forced expiratory flow between $25 \%$ and $75 \%$ of $\mathrm{FVC}$; FEF $75 \%$ : forced expiratory flow at $75 \%$ of FVC; IC: inspiratory capacity; ERV: expiratory reserve volume; TLC: total lung capacity; FRC: functional residual capacity; RV: residual volume; TL,CO: transfer factor for carbon monoxide; $\mathrm{Pa}_{2} \mathrm{O}_{2}$ : arterial oxygen tension; $\mathrm{Pa}_{\mathrm{a}} \mathrm{CO}_{2}$ : arterial carbon dioxide tension; MRC: Medical Research Council. Significantly different from NFL group. *: $\mathrm{p}<0.05$; $* *: \mathrm{p}<0.01 ; * * *: \mathrm{p}<0.001$. 
Table 4.-Lung function, Medical Research Council (MRC), five-point flow limitation (FL), high-resolution computed tomography (HRCT) score and maximal power output (WRmax) in bronchiectatic patients colonised (PA) and not colonised (non-PA) with Pseudomonas aeruginosa

\begin{tabular}{lcc}
\hline & Non-PA & PA \\
\hline Subjects & 17 & 6 \\
FVC \% pred & $90 \pm 25$ & $56 \pm 18^{* *}$ \\
FEV $\%$ pred & $75 \pm 24$ & $33 \pm 13^{* * *}$ \\
FEV1/FVC \% & $69 \pm 14$ & $51 \pm 8^{* *}$ \\
$P \mathrm{a}, \mathrm{O}_{2}$ mmHg & $79 \pm 9$ & $62 \pm 17^{* *}$ \\
MRC dyspnoea score & $1.29 \pm 0.77$ & $3.17 \pm 1.17^{* * *}$ \\
Five-point FL score & $0.29 \pm 0.59$ & $2.17 \pm 1.33^{* * *}$ \\
HRCT score & $6.44 \pm 2.79$ & $9.62 \pm 3.26^{*}$ \\
WRmax \% pred & $83 \pm 14$ & $55 \pm 7^{* *}$ \\
\hline
\end{tabular}

Data are presented as mean \pm SD. $\%$ pred: percentage of predicted; FVC: forced vital capacity; FEV1: forced expiratory volume in one second; $\mathrm{Pa}_{\mathrm{a}} \mathrm{O}_{2}$ : arterial oxygen tension; ${ }^{\#}$ : non-PA $\mathrm{n}=12$, PA n=3. *: $\mathrm{p}<0.05$; **: $\mathrm{p}<0.01 ; * * *: \mathrm{p}<0.001$.
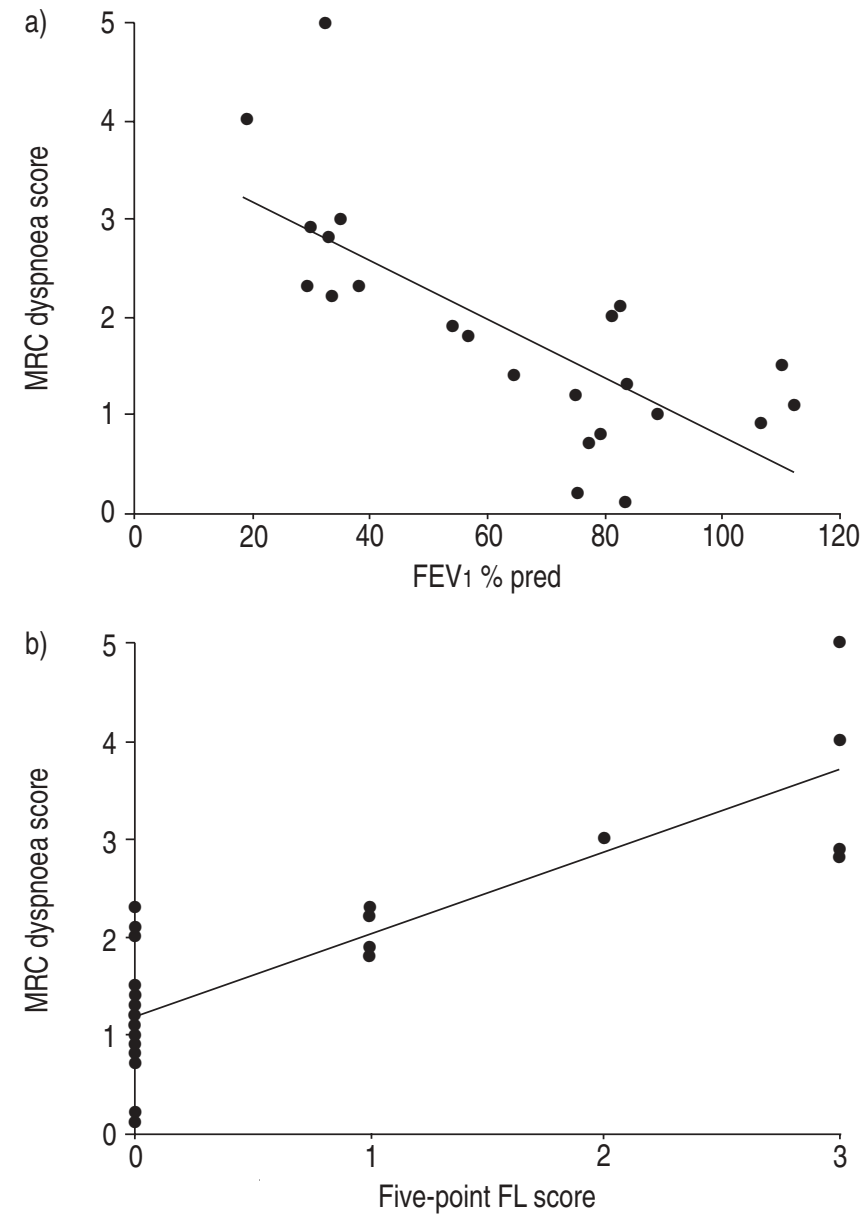

Fig. 2. - Relationships of a) Medical Research Council (MRC) dyspnoea score to forced expiratory volume in one second (FEV1) (\% pred) and b) five-point flow limitation (FL) score. a) $y=3.8-0.03 * x \pm 0.83$, $\mathrm{r}=-0.76, \mathrm{p}<0.0001 \quad(\mathrm{n}=23)$. b) $\mathrm{y}=1.1+0.9^{*} \mathrm{x} \pm 0.61, \mathrm{r}=0.85, \mathrm{p}<0.00001$ $(\mathrm{n}=23)$.

FL supine group differed significantly from the FL seated and supine groups in terms of forced vital capacity (FVC), expiratory reserve volume, residual volume/TLC, TL,CO and MRC dyspnoea score (table 3).
The MRC dyspnoea score correlated significantly with most respiratory variables studied, but the closest correlation was with the five-point FL score $(r=0.85)$ and forced expiratory volume in one second (FEV1) $(\%$ pred) $(r=-0.76)$. The relationship of MRC score to five-point FL score and FEV1 (\% pred) are depicted in figure 2.

The WRmax (\% pred) correlated significantly with most of the respiratory variables studied, except TLC, functional residual capacity, $T \mathrm{~L}, \mathrm{CO}$ and $\mathrm{Pa}, \mathrm{O}_{2}$. However, the highest correlation was found with the MRC score $(\mathrm{r}=-0.88)$, as depicted in figure 3 . There was also a close correlation with FEV1 (\% pred) ( $\mathrm{r}=-0.81)$, five-point FL score ( $\mathrm{r}=-0.78)$, peak expiratory flow ( $\%$ pred) $(\mathrm{r}=0.76)$ and HRCT score $(\mathrm{r}=-0.73)$, while that with inspiratory capacity (IC) $(\%$ pred) was poor $(\mathrm{r}=0.53)$.

The HRCT score was higher in FL than NFL patients (table 5). As shown in figure 4, there was a close correlation ( $\mathrm{r}=-0.77)$ of HRCT score and FEV1 ( $\mathrm{r}=-0.77)$ and TL,CO $(\mathrm{r}=-0.76)$. The correlation with MRC score was also significant but less close $(\mathrm{r}=0.64)$, while the correlation with WRmax was also close $(r=-0.73)$ in spite of the fact that only 15 patients were used in this analysis.

\section{Discussion}

The main findings of the present investigation are as follows: 1) tidal FL is common in sitting and/or supine positions in BB patients at rest, and is associated with higher levels of MRC dyspnoea, 2) exercise capacity is closely correlated to the degree of MRC dyspnoea, and 3) HRCT score correlates best with FEV1.

Using the NEP technique, the current authors have assessed expiratory FL during resting breathing in 23 stable BB patients: $61 \%$ were NFL, $22 \%$ were FL only supine and $17 \%$ were FL both seated and supine. A higher prevalence of tidal FL has been previously reported in stable COPD patients, particularly in the sitting position (range $42-56 \%$ of total patient population) $[11,12,18]$. This probably reflects: 1) the greater severity of airway obstruction in COPD patients (two of the NFL patients in the current study had normal lung function) and 2) the confounding effect of a restrictive pattern in the $\mathrm{BB}$ patients. In fact, expiratory FL during resting breathing is extremely rare in patients with

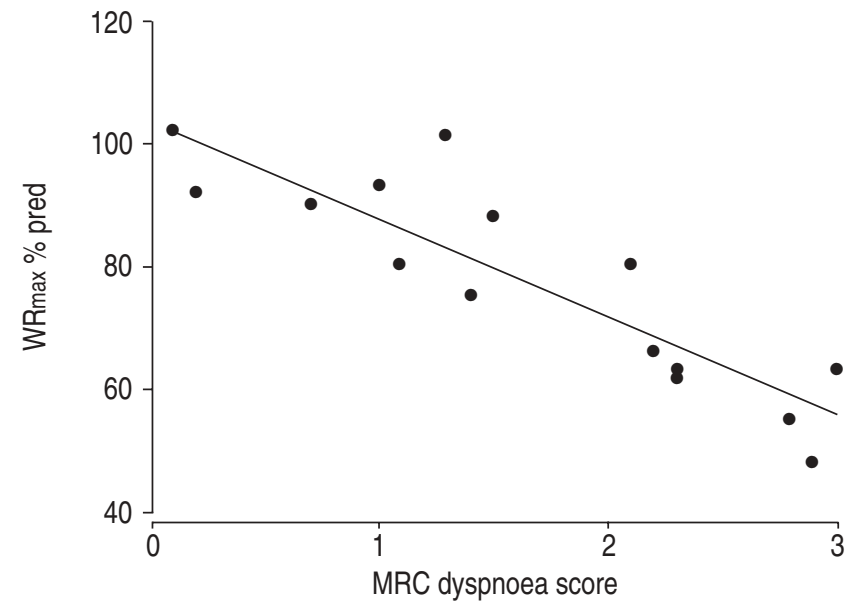

Fig. 3. - Relationship between maximum work rate ((WRmax) \% pred) and Medical Research Council (MRC) dyspnoea score. The slope indicates that the dyspnoea score increases, on average, by one MRC unit per $16 \%$ decrease in WRmax $(\%$ pred $) . y=100.5-(15.2 * x \pm 8.3)$, $\mathrm{r}=-0.88, \mathrm{p}<0.001 \quad(\mathrm{n}=15)$. 
Table 5. - Values of maximal power output (WRmax) and highresolution computed tomography (HRCT) scores in patients without (NFL) and with flow limitation (FL) seated and/or supine

\begin{tabular}{lccc}
\hline & All patients & NFL & FL \\
\hline WRmax \% pred & $77 \pm 17$ & $86 \pm 12$ & $59 \pm 7 * *$ \\
HRCT score & $7 \pm 3$ & $6 \pm 3$ & $9 \pm 3 *$ \\
\hline
\end{tabular}

Data are presented as mean \pm SD. $\%$ pred: percentage of predicted. \#: all patients $n=15$, NFL $n=10, F L n=5$; : all patients $n=23$, NFL $n=14, F L n=9$. Significantly different from NFL group. $*: \mathrm{p}<0.05 ; * *: \mathrm{p}<0.001$.
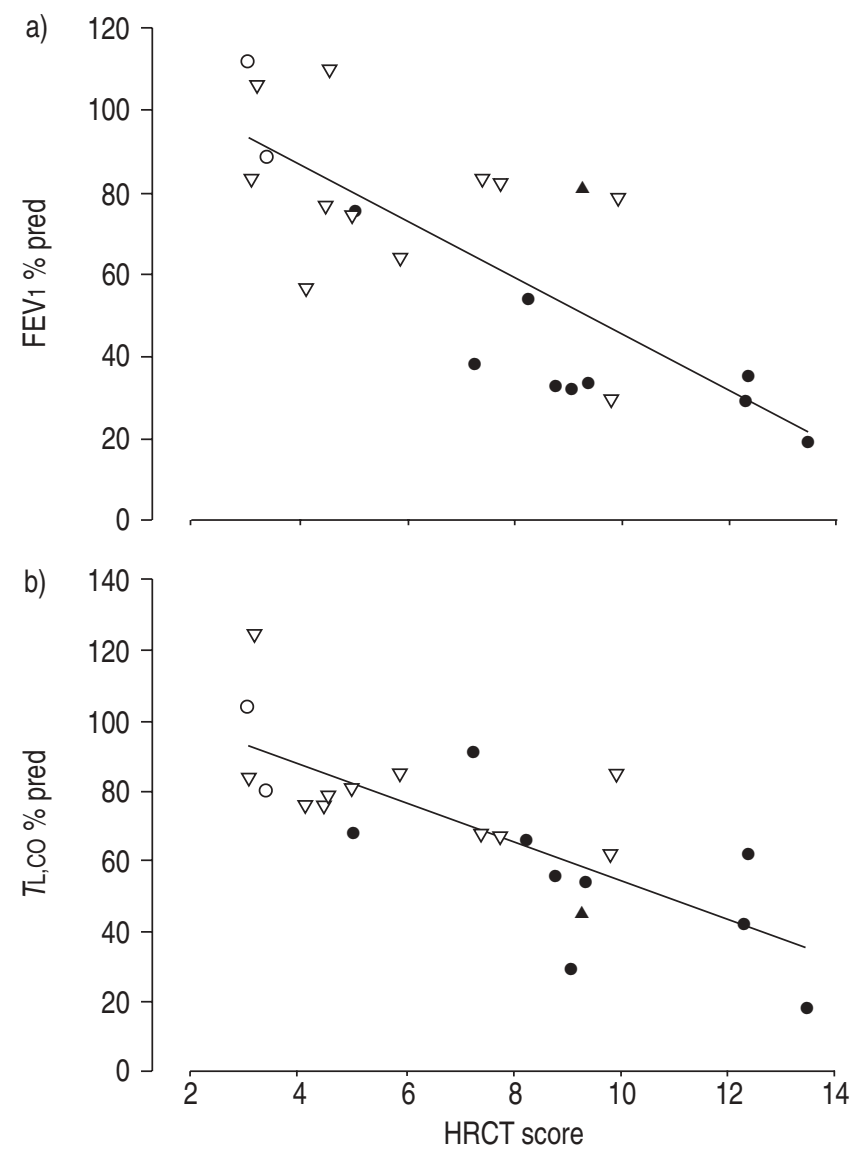

Fig. 4.-Relationship of a) forced expiratory volume in one second (FEV 1 ) (\% pred) and b) transfer factor of the lung for carbon monoxide $(T \mathrm{~L}, \mathrm{CO})(\%$ pred) to high-resolution computed tomography (HRCT) score in 23 patients with bilateral bronchiectasis. Patients with obstructive $(\triangle)$, obstructive/restrictive $(\bullet)$, restrictive $(\Delta)$ pulmonary defect and no lung function abnormality $(\bigcirc)$ are shown. a) $\mathrm{y}=114.4-6.9 * \mathrm{x} \pm 1.2, \mathrm{r}=-0.77, \mathrm{p}<0.001 \quad(\mathrm{n}=23)$. b) $\mathrm{y}=110.1-5.6 * \mathrm{x} \pm 1.1$, $r=-0.76, p<0.001(n=23)$.

restrictive respiratory disorders [23] and the single patient with a pure restrictive lung defect in this study was indeed NFL.

\section{Medical Research Council dyspnoea}

The MRC dyspnoea score correlated best with the fivepoint FL score $\left(r^{2}=0.72\right)$ and could explain $72 \%$ of its variance. In 117 stable COPD patients, the five-point FL score was also selected by stepwise logistic regression analysis as the best predictor of MRC dyspnoea score among the various independent parameters studied, which included the demographic characteristics, FEV1, FVC and FEV1/FVC [16].

In COPD patients, chronic dyspnoea, as assessed with the modified MRC scale, has been attributed mainly to dynamic pulmonary hyperinflation with concurrent inspiratory loading due to PEEPi and reduction of inspiratory muscle force [12, 16]. In view of the high prevalence of FL at rest, it is likely that PEEPi also plays a role in eliciting dyspnoea in BB patients, particularly during exercise. In fact, the MRC dyspnoea levels were significantly higher in the FL than in the NFL BB patients, with the highest scores in the subjects who were FL both seated and supine (table 3 ). Unlike in COPD [11], in BB patients the correlation of MRC dyspnoea score to IC (\% pred) was not as close as for the five-point FL score $\left(\mathrm{r}^{2}: 0.42\right.$ versus 0.72$)$. In contrast, the correlation of MRC dyspnoea score to FEV1 (\% pred) was closer in BB than in COPD patients $\left(\mathrm{r}^{2}: 0.58\right.$ versus 0.14$)$.

\section{Exercise capacity}

A very close correlation was found between WRmax (\% pred) and MRC dyspnoea score (fig. 3). To the best of the present authors' knowledge, this is the first time that such a relationship has been explored. The high correlation probably reflects the fact that the MRC dyspnoea scale (table 1) is designed to assess exercise capacity rather than severity of dyspnoea per se. The close correlation of WRmax to MRC dyspnoea score is clinically useful because, at least in BB patients, it allows the prediction of the exercise capacity to a useful approximation when cyclo-ergometry is not available or contraindicated. In contrast to COPD patients [11], the correlation of WRmax ( $\%$ pred) to IC ( $\%$ pred) was poor, reflecting the confounding effects of the restrictive pattern present in 10 of the $23 \mathrm{BB}$ patients studied.

\section{High-resolution computed tomography score}

Among all respiratory variables studied, the FEV1 correlated most closely $(\mathrm{r}=-0.77)$ with the cumulative HRCT scoring. This is in line with previous findings [24, 25] and is not surprising because most of the nine morphological indices used by the HRCT scoring method of BHALLA et al. [21] (see Methods section) are focused on the airways. As shown in figure 4 , the relationship between FEV1 (\% pred) and cumulative HRCT score did not differ appreciably among the $\mathrm{BB}$ patients with obstructive, restrictive or mixed pulmonary defect.

A close correlation for HRCT to WRmax ( $\%$ pred) ( $r=-0.73)$ was also found which suggests that the HRCT scoring method used is not only closely correlated with FEV1 but it also predicts to a useful approximation, exercise performance $\left(r^{2}=0.54\right)$. In contrast, the correlation of HRCT score to MRC dyspnoea $\left(r^{2}=0.41\right)$ and five-point FL score $\left(r^{2}=0.32\right)$ was not as good.

\section{Practical implications}

Although the MRC dyspnoea score correlated best with the five-point FL score, the correlation with FEV1 was also close in BB patients. Thus contrary to COPD patients, in which FEV1 is a poor predictor of exercise tolerance and chronic (MRC) dyspnoea, in patients with bilateral bronchiectasis the FEV1 is a useful alternative predictor of these entities.

The very close correlation found between WRmax (\% pred) 
and MRC dyspnoea score is clinically useful because the latter score provides a satisfactory prediction of WRmax when exercise testing cannot be performed because of lack of equipment, inability and/or refusal of the patient.

As expected, among all variables studied, the FEV1 correlated most closely with the cumulative HRCT scoring. It should be noted, however, that in BB patients the cumulative HRCT score was $<14$ out of a maximum 25 points, even when FEV1 was as low as $20 \%$ pred. This suggests that the HRCT scoring method used should be modified.

Finally, the results of this study confirm the association of $P$. Aeruginosa colonisation with poor lung function [26]. Furthermore, the authors have shown that PA patients have significantly higher MRC and HRCT scores and a reduced WRmax.

\section{Conclusions}

The present results indicate that in bilateral bronchiectasis patients: 1) flow limitation is common at rest in sitting and/or supine positions, and is associated with more severe Medical Research Council dyspnoea; 2) exercise capacity is closely related to the degree of Medical Research Council dyspnoea; and 3) the high-resolution computed tomography scoring used correlates best with forced expiratory volume in one second.

\section{References}

1. Kolbe J, Wells AU. Bronchiectasis: A neglected cause of respiratory morbidity and mortality. Respirology 1996; 1: 221-225.

2. Pande JN, Jain BP, Gupta RG, Guleria GS. Pulmonary ventilation and gas exchange in bronchiectasis. Thorax 1971; 26: 727-733.

3. Ip M, Lauder LJ, Wong WY, Lam WK, So SY. Multivariate analysis of factors affecting pulmonary function in bronchiectasis. Respiration 1993; 60: 45-50.

4. Cherniack NS, Vosti KL, Saxton GA, Lepper MH, Dowling HF. Pulmonary function tests in fifty patients with bronchiectasis. J Lab Clin Med 1959; 53: 693-706.

5. Cherniack NS, Carton RW. Factors associated with respiratory insufficiency in bronchiectasis. Amer $J$ Med 1966; 41: 562-571.

6. Smith IE, Jurriaans E, Diederich S, Ali N, Shneerson JM, Flower CDR. Chronic sputum production: correlations between clinical features and findings on high resolution computed tomographic scanning of the thorax. Thorax 1996; 51: 914-918.

7. Pepe PE, Marini JJ. Occult positive end-expiratory pressure in mechanically ventilated patients with airflow obstruction: the auto-PEEP effect. Am Rev Respir Dis 1982; 126: 166-170.

8. Valta P, Corbeil C, Lavoie A, et al. Detection of expiratory flow limitation during mechanical ventilation. Am J Respir Crit Care Med 1994; 150: 1311-1317.

9. Tantucci C, Ellaffi M, Duguet A, et al. Dynamic hyperinflation and flow limitation during methacholine-induced bronchoconstriction in asthma. Eur Respir J 1999; 14: 295301.
10. Sulc J, Volta CA, Ploysongsang Y, Eltayara L, Olivenstein R, Milic-Emili J. Flow limitation and dyspnoea in healthy supine subjects during methacholine challenge. Eur Respir $J$ 1999; 14: 1326-1331.

11. Diaz O, Villafranca $\mathrm{C}$, Ghezzo $\mathrm{H}$, et al. Role of inspiratory capacity on exercise tolerance in COPD patients with and without tidal expiratory flow limitation at rest. Eur Respir $J$ 2000; 16: 269-275.

12. Diaz O, Villafranca $\mathrm{C}$, Ghezzo $\mathrm{H}$, et al. Breathing pattern and gas exchange at peak exercise in COPD patients with and without tidal expiratory flow limitation at rest. Eur Respir J 2001; 17: 1120-1127.

13. Goetghebeur D, Sarni D, Grossi Y, et al. Tidal expiratory flow limitation and chronic dyspnoea in patients with cystic fibrosis. Eur Respir J 2002; 19: 492-498.

14. Regnis JA, Donnell PM, Robinson M, Alison JA, Bye PT. Ventilatory mechanics at rest and during exercise in patients with cystic fibrosis. Am J Respir Crit Care Med 1996; 154: $1418-1425$.

15. Mahler DA, Harver A. Measurement of symptoms: the benchmark of treatment. Minimizing the effects of dyspnea in COPD patients. J Respir Dis 1987; 8: 23-34.

16. Eltayara L, Becklake MR, Volta CA, Milic-Emili J. Relationship between chronic dyspnea and expiratory flow limitation in patients with chronic obstructive pulmonary disease. Am J Respir Crit Care Med 1996; 154: 1726-1734.

17. Quanjer $\mathrm{PhH}$ (ed). Standardized lung function testing. Report Working Party "Standardization of Lung Function Tests", European Community for Coal and Steel. Eur Respir J 1993; 6: Suppl. 16, 1-100.

18. Koulouris NG, Valta $\mathrm{P}$, Lavoie A, et al. A simple method to detect expiratory flow limitation during spontaneous breathing. Eur Respir J 1995; 8: 306-313.

19. Koulouris NG, Dimopoulou I, Valta P, Finkelstein R, Cosio MG, Milic-Emili J. Detection of expiratory flow limitation during exercise in COPD patients. J Appl Physiol 1997; 82: 723-731.

20. Tantucci C, Duguet A, Similowski T, Zelter M, Derenne JP, Milic-Emili J. Effect of salbutamol on dynamic hyperinflation in chronic obstructive pulmonary disease patients. Eur Respir J 1998; 12: 799-804.

21. Bhalla $\mathrm{M}$, Turcios $\mathrm{N}$, Aponte $\mathrm{V}$, et al. Cystic fibrosis: Scoring system with thin-section CT. Radiology 1991; 179: 783-788.

22. Jones NL. Interpretation of stage I exercise test results. In: Jones NL, ed. Clinical Exercise Testing. WB Saunders, Philadelphia, USA, 1997; pp. 124-149.

23. Baydur A, Milic-Emili J. Expiratory flow limitation during spontaneous breathing. Comparison of patients with restrictive and obstructive respiratory disorders. Chest 1997; 112: 1017-1023.

24. Roberts HR, Wells AU, Milne DG, et al. Airflow obstruction in bronchiectasis: correlation between computed tomography features and pulmonary function tests. Thorax 2000; 55: 198-204.

25. Wong-You-Cheong JJ, Leahy BC, Taylor PM, Church SE Airways obstruction and bronchiectasis: Correlation with duration of symptoms and extent of bronchiectasis on computed tomography. Clin Radiol 1992; 45: 256-259.

26. Evans SA, Turner SM, Bosch BJ, Hardy CC, Woodhead MA. Lung function in bronchiectasis: the influence of Pseudomonas aeruginosa. Eur Respir J 1996; 9: 1601-1604. 